\title{
A afetividade na relação professor-aluno: Alicerces para a aprendizagem
}

\section{significativa}

\author{
Affectiveness in the teacher-student relationship: Foundations for meaningful learning \\ Afectividad en la relación profesor-estudiante: Fundamentos para un aprendizaje significativo
}

Recebido: 18/07/2021 | Revisado: 25/07/2021 | Aceito: 28/07/2021 | Publicado: 04/08/2021

Maria Dos Santos Guimarães

ORCID: https://orcid.org/0000-0003-3705-585X

Universidade de Cuiabá, Brasil

E-mail: mariaguimaraes_estetica@yahoo.com.br

Cilene Maria Lima Antunes Maciel

ORCID: https://orcid.org/0000-0003-4606-802X

Universidade de Cuiabá, Brasil

E-mail: cilenemlamaciel@gmail.com

\begin{abstract}
Resumo
Trata-se de um recorte da pesquisa de mestrado do Programa PPGEn UNIC/IFMT, em processo final de desenvolvimento, objetivando compreender a relevância da afetividade como impulsionadora da relação professoraluno para a Aprendizagem Significativa no âmbito da Educação Básica. Constitui-se de um estudo de caso, onde utilizou-se uma entrevista com roteiro semiestruturado como instrumento de coleta de dados, sendo os dados interpretados por análise da narrativa. Foram entrevistados docentes e discentes, de 2 (duas) escolas da rede pública da Educação Básica, de Várzea Grande, Mato Grosso. No presente artigo, considerou-se apenas as análises dos relatos obtidos pelos docentes. Os resultados preliminares da pesquisa, evidenciam a necessidade de priorizar as relações professor-aluno para estimular os laços afetivos, como uma ferramenta relevante no ensino, e compete ao professor emprega-la em seu benefício, fazendo com que os alunos tenham um maior interesse em sua disciplina, e maior desenvolvimento intelectual. No cotidiano de sala de aula a comunicação é imprescindível para o desempenho dos processos de interação existentes entre professor e aluno. Para os docentes entrevistados o início do processo educativo está em conhecer o que se tem no cognitivo do aluno, para sobre essa base, construir o novo, e isso, só é possível com laços afetivos sólidos entre professor-aluno; e essa relação é manifestada como um fator de fundamental importância para se avaliar a qualidade da trajetória estudantil.
\end{abstract}

Palavras-chave: Afetividade; Aprendizagem significativa; Educação básica; Práticas de ensino.

\begin{abstract}
This is an excerpt from the master's research of the PPGEn UNIC/IFMT Program, in the final development process, aiming to understand the relevance of affectivity as a driver of the teacher-student relationship for Meaningful Learning in the context of Basic Education. It consists of a case study, where an interview with a semi-structured script was used as a data collection instrument, with the data being interpreted by narrative analysis. Teachers and students from 2 (two) public schools of Basic Education in Várzea Grande, Mato Grosso, were interviewed. In this article, only the analyzes of the reports obtained by the professors were considered. The preliminary results of the research show the need to prioritize teacher-student relationships to stimulate affective bonds, as a relevant tool in teaching, and it is up to the teacher to use it for their benefit, making students have a greater interest in his discipline, and greater intellectual development. In everyday classroom, communication is essential for the performance of existing interaction processes between teacher and student. For the teachers interviewed, the beginning of the educational process is to know what is in the student's cognitive, to build the new on this basis, and this is only possible with solid affective ties between teacher-student; and this relationship is manifested as a factor of fundamental importance to assess the quality of the student trajectory.
\end{abstract}

Keywords: Affectivity; Meaningful learning; Basic education; Teaching practices.

\section{Resumen}

Este es un extracto de la investigación de maestría del Programa PPGen UNIC / IFMT, en el proceso de desarrollo final, con el objetivo de comprender la relevancia de la afectividad como motor de la relación maestro-alumno para el Aprendizaje Significativo en el contexto de la Educación Básica. Consiste en un estudio de caso, donde se utilizó una entrevista con un guión semiestructurado como instrumento de recolección de datos, siendo los datos interpretados por análisis narrativo. Se entrevistó a profesores y alumnos de 2 (dos) escuelas públicas de Educación Básica en Várzea Grande, Mato Grosso. En este artículo solo se consideraron los análisis de los informes obtenidos por los profesores. Los resultados preliminares de la investigación muestran la necesidad de priorizar las relaciones profesor- 
alumno para estimular los lazos afectivos, como herramienta relevante en la docencia, y le corresponde al docente utilizarla en su beneficio, haciendo que los alumnos tengan un mayor interés en su disciplina. y un mayor desarrollo intelectual. En el aula cotidiana, la comunicación es fundamental para el desempeño de los procesos de interacción existentes entre profesor y alumno. Para los docentes entrevistados, el inicio del proceso educativo es conocer lo que hay en el cognitivo del alumno, construir lo nuevo sobre esta base, y esto solo es posible con sólidos vínculos afectivos entre docente-alumno; y esta relación se manifiesta como un factor de fundamental importancia para evaluar la calidad de la trayectoria del estudiante.

Palabras clave: Afecto; Aprendizaje significativo; Educación básica; Prácticas de enseñanza.

\section{Introdução}

O presente estudo constitui-se de um recorte da pesquisa de mestrado do Programa PPGEn UNIC/IFMT, em processo final de desenvolvimento, tendo em vista compreender a relevância da afetividade como fator impulsionador da relação professor-aluno para a Aprendizagem Significativa no âmbito da Educação Básica. Para tanto parte-se do princípio que, conforme Veras e Ferreira (2010) afirmam, a afetividade se constitui como um fator de vasta importância no processo de desenvolvimento de um indivíduo, assim como na sua relação com o outro, visto que é por meio do outro que esse indivíduo pode delimitar-se como pessoa no decorrer de um processo constante e permanente de construção.

O ser humano é capaz de criar ou transformar certas relações que estejam se desenvolvendo negativamente em algo positivo, dentre as relações positivas se incluem: otimismo, divertimento e sucesso profissional, no ensino e na vida (Portelada, 2011). Ao reconhecer a atenção, carinho e respeito do professor, os alunos adquirem confiança, admiração, amizade e respeito na relação, favorecendo a aprendizagem (Antunes, 2016). Atualmente, muito mais que preocupar-se com a leitura e escrita ou com operações matemáticas, o docente deve atentar-se com a capacidade do aluno em compreender suas emoções, tentar compreender as dos demais e ainda auxiliá-lo na gestão de suas emoções frente às situações adversas.

A Teoria da Aprendizagem Significativa, cunhada pelo psicólogo norte-americano David Paul Ausubel (1963) é considerada como um mecanismo humano, por excelência, para adquirir e armazenar a vasta quantidade de ideias e informações representadas em qualquer campo de conhecimento. Nesse sentido, Carvalho; Maciel e Herrea (2017), afirmam que o fortalecimento das relações entre professores e alunos é essencial na edificação de valores e conhecimentos que alicerçam as bases emocionais, profissionais e humanas, destes, nas práticas de ensino, sendo cogente promover uma relação saudável e comprometida no processo educativo; buscando caminhos que orientem tais relações visando o sucesso desse processo.

O estudo vem se debruçando em responder a seguinte indagação: no processo de ensino, qual a importância da afetividade para a aprendizagem significativa? O afeto existente entre professor e aluno, pode tornar-se um instrumento mediador para a aprendizagem significativa? Nesse contexto, é pertinente ressaltar que, para que haja uma Aprendizagem Significativa a comunicação em sala de aula, e no espaço escola como um todo, deve ser vista como uma ferramenta imprescindível no desempenho dos processos de interação professor-aluno, o que envolve fatores bastante complexos, e em razão disso, não deve jamais ser limitada unicamente ao compartilhamento de informação em via única.

\section{O Processo Ensino-aprendizagem e a Afetividade}

Para a aprendizagem humana em todo seu processo, a interação social e a mediação do outro são de suma importância. No ambiente escolar, a interação professor-aluno é imprescindível para o sucesso do processo ensinoaprendizagem. Por essa razão, há uma infinidade de trabalhos e pesquisas na área da educação que abordam essa temática, sempre enfatizando a interação social e a função do professor mediador, como requisitos básicos para qualquer prática educativa eficiente (Rodrigues \& Garms, 2006). Há uma ampla demonstração sobre o tema e uma forte valorização do diálogo como um importante instrumento na constituição dos sujeitos. 
Para Rodrigues e Garms (2006) a função primordial da educação é transformar sujeitos e mundo em algo melhor. O homem só entende o processo de construção do saber quando aprende a problematizar suas práticas. E, esse processo visa a formação do educando, como será capacitado, e, de quais formas a escola pode auxiliar em seu processo de desenvolvimento.

A afeto, se configura como parte integrante no desenvolvimento humano, tanto nos relacionamentos interpessoais, quanto na construção do conhecimento. Em vista disso, a afetividade e os seus efeitos também se tornaram objeto de estudos na esfera científica, na maior parte das vezes executados por estudiosos da área educacional, e outras áreas vinculadas à psicologia (Sousa; Santos \&Valverde, 2016). Conjuntamente com a inteligência, a afetividade, é capaz de contribuir expressivamente para o sucesso da aprendizagem, pois são indispensáveis ao desenvolvimento psíquico do estudante, que ocorre no ambiente social.

A afetividade, no ambiente escolar, sempre foi colocada em segundo plano, pois quando se falava em aprendizagem, acreditava-se que essa era uma função exclusiva da razão. No entanto, hodiernamente, muitos estudos têm voltado seu campo de visão para a dimensão afetiva do comportamento humano. Com base em abordagens que enfatizam às interações sociais, e destacando o papel determinante do outro no desenvolvimento, bem como, na constituição de um indivíduo, tem se estabelecido uma tendência fundamentada em consolidar certas teorias que se preconizam uma ótica mais integrada do ser humano.

Para Antunes (2006), a aprendizagem é uma mudança comportamental que resulta da experiência. Neste sentido, ressalta-se uma forma de adaptação ao ambiente, que não está associada apenas à ideia de carinho, bondade e ternura, mas significa também passar segurança, educar com firmeza no cumprimento das regras, porque dessa forma a criança estará sendo preparada para a vida. Maldonado (1994) aborda o medo e a desconfiança como fatores que dificultam o relacionamento interpessoal, assinalando que o amor pode estar escondido sob camadas de mágoa, medo, tristeza, ressentimento, decepção, vergonha e raiva.

Na prática, nota-se uma grande preocupação dos educadores em procurar fórmulas para alcançar a disciplina em sala de aula, enquanto outros já desistiram, dizendo não haver solução. Todavia, acredita-se que essa solução possa ser atingida quando os sentimentos humanos forem considerados, tanto dos professores, quanto dos alunos, encontrando no ato afetivo o caminho para a compreensão dos sujeitos em constante processo de construção.

A afetividade, apresenta uma concepção bastante vasta, que envolve uma gama muito maior de manifestações, abrangendo sentimentos, isto é origem psicológica; e emoções, ou seja, de origem biológica. Assim, a afetividade representa um período mais tardio da evolução da criança, quando os elementos simbólicos surgem. É, portanto, com o surgimento de tais elementos que as emoções são transformadas em sentimentos. A possibilidade de representação, que por consequência implica em uma transferência para o plano mental, e confere aos sentimentos uma determinada moderação e durabilidade.

Neste sentido, é fundamental acreditar que o aluno é capaz de aprender, mesmo que seja dentro de suas limitações, alguma coisa ele irá aprender. Existe a concepção de que todos devem aprender a mesma coisa ao mesmo tempo, porém cada um tem uma experiência de vida, tem seu interesse e sua motivação. $O$ docente precisa ter a sensibilidade de ouvir seu aluno, conhecer sua realidade e criar um clima afetivo na sala de aula, o que possibilitará ao educando desenvolver sua auto-estima, contribuindo para estimular a aprendizagem.

\section{Correlações entre Afetividade e Cognição e a Aprendizagem Significativa de Ausubel}

Piaget (1980), estudando o afeto e a cognição, considerou o desenvolvimento intelectual como um processo compreendido sob um aspecto cognitivo e um afetivo. Segundo essa teoria, o conhecimento se desenvolve quando as crianças fazem assimilações e acomodações das experiências. Isso pode ocorrer por ações que são pensamentos ao nível 
representacional. Com as crianças mais novas as construções ocorrem quase exclusivamente quando há ações sensório-motoras sobre os objetos, ou seja, quando a criança brinca sem noção de regras e a inteligência trabalha por percepções (simbólico) e ações (motor) por deslocamentos do próprio corpo.

A dimensão afetiva, segundo Sousa, Santos e Valverde (2016), inclui sentimentos, interesses, impulsos ou tendências, assim como "vontade" e valores, se constituindo como fator energético dos padrões de comportamento cujos aspectos cognitivos referem-se apenas às estruturas. Na verdade, não existe conduta, por mais intelectual que seja, que não compreenda padrões afetivos como "motivos". Acerca disso, os citados autores se remetem à concepção de Piaget, afirmando que tanto o aspecto cognitivo quanto o afetivo desempenham papéis chaves no desenvolvimento intelectual.

Segundo Piaget (1980) a criança chega à etapa da autonomia crítica quando há consenso nas regras, onde o respeito às regras decorre de acordos mútuos ou coletivos. É quando surge a capacidade de estabelecer relações cooperativas genuínas. Problemas de aprendizagem, como as dificuldades de compreensão, interpretação, leitura, escrita e raciocínio lógico, e outros, são difíceis de serem compreendidos. Para avançar na compreensão do não aprender, é preciso olhar para a criança/adolescente em sua totalidade afetiva e cognitiva, considerando a afetividade e a inteligência como aspectos inseparáveis, irredutíveis e complementares da conduta humana.

Sendo a vida afetiva e cognitiva inseparáveis, embora distintas, o ato de inteligência pressupõe uma regulação energética interna (interesse, esforço, facilidade, etc), o interesse e a relação afetiva entre a necessidade e o objeto susceptível de satisfazê-la. É importante a criança perceber no docente um amigo, pois o laço afetivo influenciará na aquisição do conhecimento. Na dinâmica do processo ensino-aprendizagem, está ainda a moralidade, que se constitui na obediência às regras do jogo. A moralidade é o palco, onde a afetividade e a razão estão, via de regra, sob a forma de confronto. Logo, a afetividade interfere no uso da razão (Piaget, 1980).

Considerando os aspectos cognitivos do processo de apropriação de conhecimentos, na década de 1960, o psicólogo norte-americano David Paul Ausubel, trouxe as formulações iniciais da Teoria da Aprendizagem Significativa, por meio de propostas psicoeducativas, descritas na obra "Psicologia Educacional", que segundo Moreira e Mansini (2001), explanam a aprendizagem escolar e o processo de ensino a partir de um marco distanciado dos princípios condutistas.

Para Ausubel (1963), as novas informações recebidas no ambiente escolarizado podem ser assimiladas por relações, as quais "ligam" os conteúdos a serem aprendidos com informações disponíveis na estrutura cognitiva do aprendiz. Assim, verifica-se que a aprendizagem ocorre de modo não-literal e não arbitrário, ou seja, significativamente. A ideia central de Aprendizagem Significativa é a reorganização da estrutura cognitiva, ou seja, um processo onde a informação nova se relaciona com algo relevante na estrutura do conhecimento do estudante. É uma tentativa de fornecer sentido ou estabelecer relações de modo não arbitrário e substancial entre os novos conhecimentos e conceitos existentes (Ausubel; Novak \& Hanesian, 1980).

Nesse contexto, Moreira (2006) explica que segundo Ausubel, o conhecimento prévio é um dos pilares para a Aprendizagem Significativa, um processo ao qual uma nova informação relaciona-se com um aspecto relevante da estrutura de conhecimento do indivíduo. Esse processo envolve a interação da nova informação com uma estrutura prévia de conhecimento específico.

$\mathrm{Na}$ aprendizagem significativa, o aprendiz não é um receptor passivo. Longe disso. Ele deve fazer uso dos significados que já internalizou, de maneira substantiva e não arbitrária, para poder captar os significados dos materiais educativos. Nesse processo, ao mesmo tempo que está progressivamente diferenciando sua estrutura cognitiva, está também fazendo a reconciliação integradora de modo a identificar semelhanças e diferenças e reorganizar seu conhecimento. Quer dizer, o aprendiz constrói seu conhecimento, produz seu conhecimento (Moreira, 2005, p. 5). 
A Aprendizagem Significativa ocorre quando as novas informações, incorporam uma estrutura lógica e interagem com outros conceitos relevantes, inclusivos e claros, previamente estabelecidos na estrutura cognitiva por processo de assimilação em equidade sob o processo de diferenciação, elaboração e estabilidade. É por meio desse processo de interatividade que há apropriação uma experiência consciente, claramente articulada e precisamente diferenciada quanto a sinais, símbolos, conceitos e proposições potencialmente e incontestavelmente significativos que estão estritamente relacionados a estrutura cognitiva e a ele incorporados.

[...] a Aprendizagem Significativa é um processo de ensino-aprendizagem, em que o aluno como ser biopsicossocial e participante deste processo, apresenta motivação de aprender, assim, compreende, reflete e atribui novos conceitos, partindo de conhecimentos e experiências prévias, modificando os significados existentes, por meio da organização e integração na estrutura cognitiva dos conceitos prévios e novos, tornando-os significativos, os quais, necessariamente, são transferidos para outras situações que vivenciar (Agra et al., 2019, p. 263).

Veras e Ferreira (2010) afirmam que a afetividade se constitui como um fator de vasta importância no desenvolvimento de um indivíduo, e na sua relação com o outro, pois, é por meio do outro que esse indivíduo pode delimitarse como pessoa no decorrer de um processo constante e permanente de construção. É imprescindível que o docente esteja profundamente envolvido nesse processo; e considere a afetividade como parte do desenvolvimento, sobretudo, buscando uma Aprendizagem Significativa, contribuindo na formação integral de seus alunos, e para uma vivência mais positiva do processo de ensino-aprendizagem.

\section{Metodologia}

Trata-se de um recorte da pesquisa de mestrado do Programa PPGEn UNIC/IFMT, em processo final de desenvolvimento, visando compreender a relevância da afetividade como impulsionadora da relação professor-aluno para a Aprendizagem Significativa no âmbito da Educação Básica.

A pesquisa foi delineada como estudo de caso por se tratar de investigação empírica que investiga um fenômeno contemporâneo dentro de seu contexto real, sobretudo quando os limites entre o fenômeno e o contexto não estão claramente definidos e o pesquisador tem pouco ou nenhum controle. O estudo de caso é visto como um método rigoroso de pesquisa, que expõe o uso de uma abordagem sistêmica e sociológica, apoiando-se em exemplos diversos, e comparando com outros tipos de pesquisa (Yin, 2015).

Para Gil (2010, p. 54) o estudo de caso,

[...] consiste no estudo profundo e exaustivo de um ou poucos objetos, de maneira que permita seu amplo e detalhado conhecimento, tarefa praticamente impossível mediante outras metodologias, sendo esta uma modalidade de pesquisa utilizada nas ciências sociais e biomédicas, o mesmo autor explicita que essa modalidade pode ser dividida em várias etapas como: formulação do problema, definição da unidade-caso, determinação do número de casos, elaboração do protocolo, coleta de dados, avaliação e análise dos dados e preparação do relatório.

A abordagem qualitativa conferida ao estudo, considera, segundo Lakatos (2008), que há uma relação dinâmica entre a realidade e o sujeito, isto é, um vínculo indissociável entre o que é proposto e a personalidade do sujeito, e que não pode ser traduzido. Assim, a interpretação dos fenômenos e a atribuição de significados são fundamentais. Portanto, não requer o emprego de métodos e técnicas estatísticas, visto que, a fonte direta para coleta de dados é o ambiente natural, enquanto que o pesquisador é o instrumento-chave. 
Esse tipo de abordagem, justifica o emprego da técnica de análise de conteúdo para tratamento dos dados, por tratarse de uma técnica de análise das comunicações, que analisa o que foi dito nas entrevistas ou observado pelo pesquisador; sendo o objeto de estudo é o registro em si, presente em um texto, um documento, uma fala ou um vídeo.

[...] o termo análise de conteúdo designa: um conjunto de técnicas de análise das comunicações visando a obter, por procedimentos sistemáticos e objetivos de descrição do conteúdo das mensagens, indicadores (quantitativos ou não) que permitam a inferência de conhecimentos relativos às condições de produção/recepção (variáveis inferidas) destas mensagens (Bardin, 2016, p. 47).

Foram entrevistados 8 (oito) docentes e 24 (vinte e quatro) discentes, de 2 (duas) escolas da rede pública da Educação Básica, do município de Várzea Grande, Estado de Mato Grosso. Adotou-se como instrumento de pesquisa uma entrevista com roteiro semiestruturado, tendo em visa se dispor de questões acerca da investigação realizada (Quadro 1).

Quadro 1 - Roteiro de entrevista semiestruturada para os professores.

\begin{tabular}{l} 
1. Você usa a afetividade para uma melhor aprendizagem? \\
2. O quanto você acredita que a comunicação ineficiente implica na aprendizagem? \\
3. Ouvir o aluno em sua essência, cria uma oportunidade para aprendizagem? \\
4. A proximidade entre professor e aluno, favorece a aprendizagem? \\
5. Valorizar o conhecimento prévio influência aprendizagem? \\
\hline
\end{tabular}

Fonte: Autores.

No que se refere aos aspectos éticos, a pesquisa foi aprovada pelo Comitê de Ética em Pesquisa (CEP) da Universidade de Cuiabá (UNIC), sob parecer n ${ }^{\circ}$ 4.560.112. Foi preservado o anonimato dos participantes, adotando-se códigos para identificação dos relatos.

\section{Resultados e Discussão}

Para desenvolvimento do presente estudo, preconizou-se apenas a análise dos relatos obtidos por parte dos docentes. Visando atender aos objetivos propostos, as falas foram analisadas em 2 (duas) categorias; sendo em seguida, interpretados à luz do referencial teórico.

Assim, a Figura 1, mostra a categorização desenvolvida para análise, como base na proposta do estudo, ou seja, "A afetividade como ferramenta de aprendizagem significativa". Sobre isso, Carvalho, Maciel e Herrea (2017) afirmam que é preciso considerar que no ambiente escolar os laços afetivos permitem ao educador melhor compreensão de seus educandos, suas necessidades, comportamentos, limitações e até mesmo traumas. 
Figura 1 - Categorias de análises.

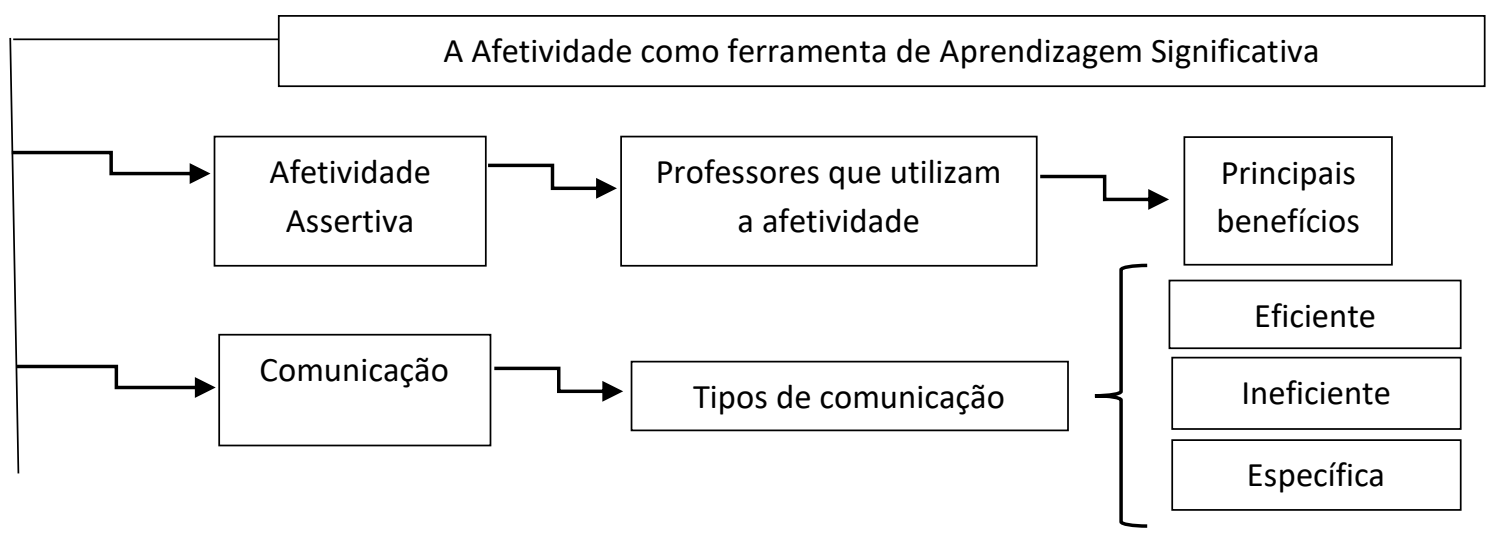

Fonte: Dados da Pesquisa (2021).

Sendo assim, a análise das declarações fornecidas para a presente pesquisa, corroboram como Nery (2009, p. 8) que afirma que "profissionais de diferentes áreas do conhecimento têm voltado sua atenção para defender a associação entre o afeto e o aprender".

A Figura 2 traz a representação da categoria "Afetividade Assertiva” na Aprendizagem Significativa", onde a maior parte dos participantes da pesquisa afirmam que usam a afetividade como uma ferramenta que visa facilitar o processo de aprendizagem.

Figura 2 - Representação da categoria: Afetividade Assertiva.

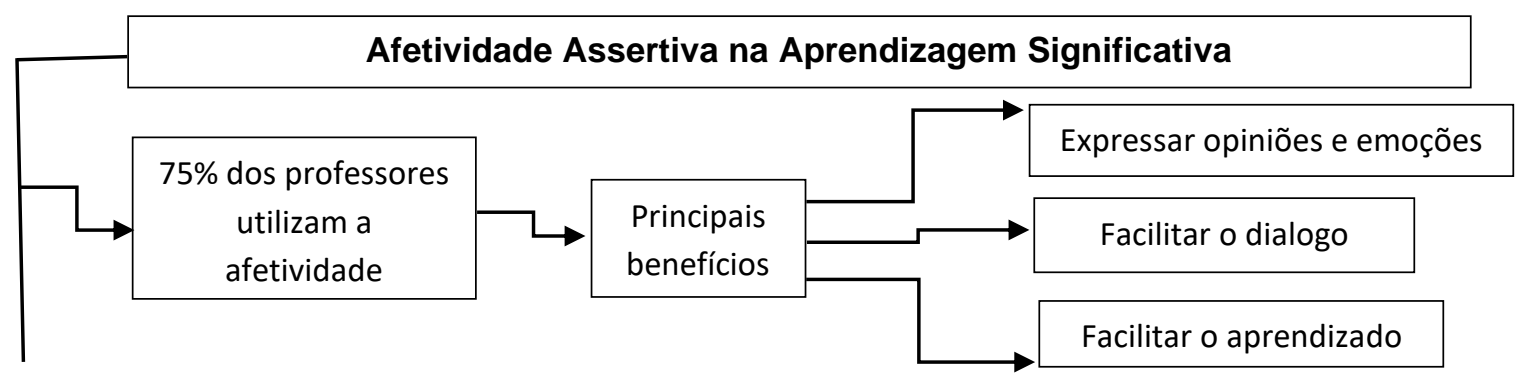

Fonte: Dados da Pesquisa (2021).

Nesse sentido, pode-se inferir que não existe uma aprendizagem unicamente cognitiva ou racional, uma vez que, de acordo com Silveira (2010) os aspectos afetivos que constituem a personalidade do aluno não estão dissociados durante o período em que se encontra em sala de aula. Para a citada autora, o pensar e o sentir, se complementam.

As falas, em destaque no Quadro 2, mostram que os professores percebem a importância do afeto na relação alunoprofessor, e afirmam se utilizarem da afetividade na busca de maior interação com seus alunos, e de resultados positivos dentro do processo de ensino-aprendizagem, por facilitar a comunicação entre ambos, o que também auxilia a identificar as dificuldades dos alunos. 
Quadro 2 - Categoria 1 - A Afetividade Assertiva na Aprendizagem Significativa.

\begin{tabular}{|c|c|}
\hline Categorização & Excertos das respostas \\
\hline \multirow{8}{*}{ Afetividade Assertiva } & P2- "Utilizar a afetividade [...] você abre espaço para que o aluno [...]" \\
\hline & P3- "[...] creio que é a melhor forma de desenvolver o aluno $[\ldots] "$ \\
\hline & P4- "[...] a afetividade ela é uma das ferramentas cruciais pra que o aluno \\
\hline & possa se desenvolver $[\ldots] "$ \\
\hline & P5- "Cultivar a afetividade no processo de ensino aprendizagem significa \\
\hline & construir boas relações $[\ldots .] ”$. \\
\hline & $\begin{array}{l}\text { P7- “[...] então eu acho que a afetividade, a sensibilidade é muito } \\
\text { importante pro desenvolvimento dos alunos." }\end{array}$ \\
\hline & $\begin{array}{c}\text { P8- "[...] importante para alcançar resultado positivo no processo de ensino- } \\
\text { aprendizagem }[\ldots] "\end{array}$ \\
\hline
\end{tabular}

De acordo com Antunes (2016) trabalhar a afetividade é algo de suma importância em sala de aula, e em todo contexto escolar, haja vista que, é a partir de suas condições psicológicas que o educando formará sua personalidade, isto é, um educando pensado de forma integral e não fragmentada, nessa articulação entre o orgânico e o contexto sociocultural. Sobre isso, é dado destaque à parte da fala do Professor 7, que diz: “[...] a sensibilidade é muito importante pro desenvolvimento dos alunos".

Por se tratar de um processo de construção de conhecimento e formação do sujeito por meio do sistema educacional formal, é que esse assunto deve ser considerado com extremo comprometimento e responsabilidade, pois, conforme explica Nery (2009, p. 13) o educando é "no viés racionalista, dividido em duas partes: uma cognitiva e outra afetiva".

Para Kieckhoefel (2011), isso significa que, no ambiente escolar, além de dar carinho, é necessário aproximar-se do aluno, dar-lhe atenção, conhecê-lo, saber ouvir e valorizá-lo; que o olhar do educador, é indispensável para sua aprendizagem e que, é por meio das emoções que o aluno exterioriza seus desejos e vontades.

Com base nisso, a Figura 3, trata da categoria "A afetividade e a Comunicação". Na visão de Silveira (2010) por meio de uma comunicação eficiente, o professor propicia maior atenção aos seus alunos, acompanhando o seu desempenho escolar, e acreditando nas capacidades dos educandos e mostrando por meio do respeito, que o erro faz parte do processo de construção do conhecimento.

Figura 3 - Representação da Categoria 2: "A afetividade e a Comunicação".

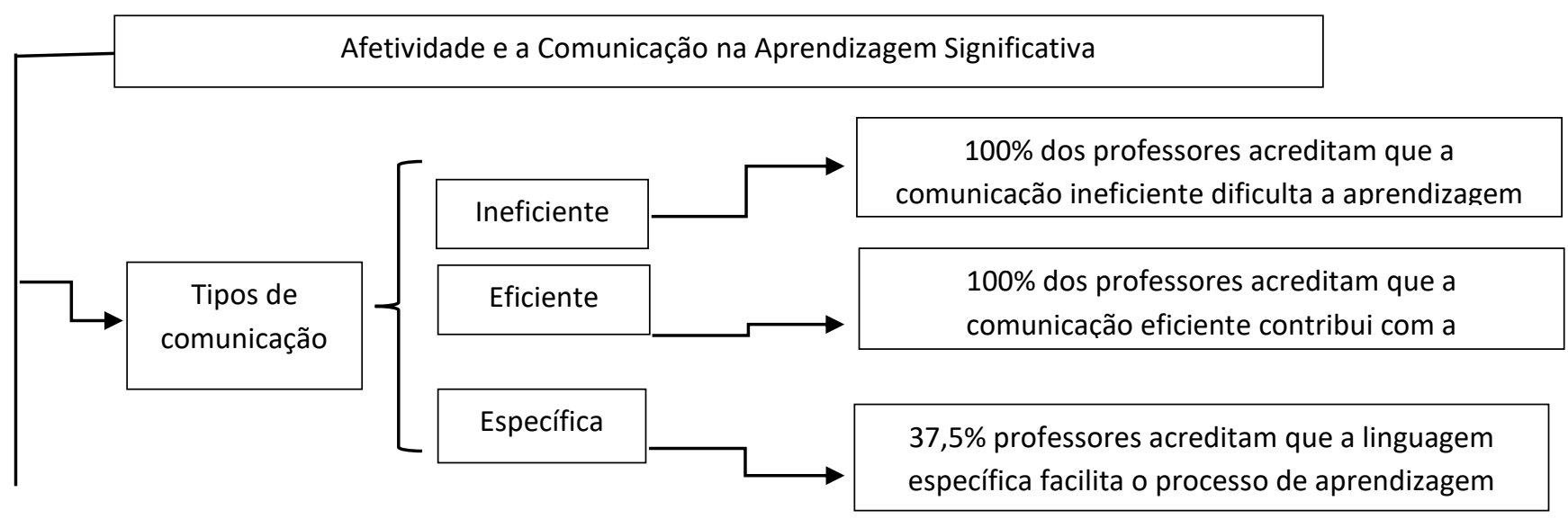

Fonte: Dados da Pesquisa (2021). 
A afetividade é capaz de possibilitar uma espécie de comunicação própria capaz de trazer entusiasmo, de fazer o aluno se dedicar com comprometimento, adquirir responsabilidade e faz a diferença em sala de aula, proporcionando que o verdadeiro apreender e aprender aconteça de forma consistente. No âmbito sociológico, o papel da comunicação, segundo Figaro (2012) é de transmitir significados entre os indivíduos tendo em vista a sua integração na organização social. Portanto, a comunicação é empregada como mediadora na interação social entre os homens, os quais se encontram em constante relação uns com os outros.

Contudo, Figaro (2012) destaca que para que a comunicação aconteça de fato, é necessário que se estabeleça uma relação de interdependência entre a fonte e o receptor, um elemento precisa do outro para que ambos possam existir. Nesse contexto, se faz importante destacar que os professores, de modo geral, precisam ter o desejo de que os seus alunos aprendam. E, sobre isso, Rodrigues (1976) lembra que a comunicação é um componente básico da vida social, e o aprendizado humano se inicia já nos primeiros dias de vida.

Nota-se claramente nas falas dos docentes, em destaque no Quadro 3, que a ineficiência da comunicação no ambiente escolar, implica diretamente no insucesso da aprendizagem. Nesse sentido, Figaro (2012) afirma que, essa ineficiência na comunicação, pode gerar problemas e acarretar em sérias consequências, pois, quando os objetivos da fonte e do receptor se mostram incompatíveis a comunicação é rompida.

Quadro 3 - Categoria 2 - A Afetividade e a Comunicação na Aprendizagem Significativa.

\begin{tabular}{|c|c|}
\hline Categorização & Excertos das respostas \\
\hline \multirow{6}{*}{$\begin{array}{l}\text { Comunicação } \\
\text { Ineficiente. }\end{array}$} & P2- "Acaba causando um bloqueio no aluno, $[\ldots]$ ". \\
\hline & $\begin{array}{l}\text { P4- "[...] uma má comunicação, você não consegue é chegar em lugar } \\
\text { nenhum" }\end{array}$ \\
\hline & P5- “[...] não dialoga os saberes com as vivências cotidianas.” \\
\hline & P6- [...] Se ele não tem a compreensão ele não consegue se comunicar [...]" \\
\hline & P7- "[...] a ineficiência da comunicação atrapalha quase que 70\%[...]" \\
\hline & P8- "[...]acredito que prejudica muito o processo $[\ldots] "$ \\
\hline
\end{tabular}

Acerca disso, Silveira (2010) afirma que é fundamental acreditar que o aluno é capaz de aprender, mesmo que seja dentro de suas limitações, alguma coisa ele irá aprender. Na visão da autora, há a concepção de que todos devem aprender a mesma coisa ao mesmo tempo, porém cada um tem uma experiência de vida, tem seu interesse e sua motivação.

A relação entre professor e aluno, segundo Kieckhoefel (2011) deve ser sempre baseada no diálogo e respeito à ideia um do outro, ouvir e falar como condição da compreensão e entendimento para que ambos cresçam e possam fazer sua reflexão sobre o que pensam e dizem.

Os excertos das respostas destacadas no Quadro 4, são indiscutivelmente, para uma escuta diferenciada por parte do docente, conforme sua relação com cada aluno; uma vez que, cada um têm uma realidade dentro e fora da escola, e cabe ao professor identificar, e buscar escutá-lo de forma individual. 
Quadro 4 - Categoria 2 - A Afetividade e a Comunicação na Aprendizagem Significativa.

\begin{tabular}{|c|c|}
\hline Categorização & Excertos das respostas \\
\hline \multirow{5}{*}{$\begin{array}{l}\text { Comunicação } \\
\text { Eficiente. }\end{array}$} & P3- “[...] comunicação é uma via de mão dupla [...]” \\
\hline & P4- “[...] é o que nos orienta dentro de um determinado espaço, $[\ldots]$ " \\
\hline & $\begin{array}{l}\text { P5- "A comunicação didático-pedagógica se refere ao diálogo constante e } \\
\text { construtivo [...]" }\end{array}$ \\
\hline & $\begin{array}{l}\text { P7- "[...] você conseguir se comunicar, o aluno te compreender e você } \\
\text { compreender ele, é quase } 100 \% \text { da compreensão da aula }[\ldots] "\end{array}$ \\
\hline & $\begin{array}{l}\text { P8- "[...] importante para alcançar resultado positivo no processo de ensino- } \\
\text { aprendizagem." }\end{array}$ \\
\hline
\end{tabular}

Portanto, o professor precisa desenvolver, em si mesmo, uma certa sensibilidade para ouvir o seu aluno, e conhecer a sua realidade, assim como, criar um clima afetivo dentro de sala de aula, pois, conforme menciona Silveira (2010) é deste modo, que se possibilitará ao educando desenvolver sua auto-estima, e por consequência irá contribuir consideravelmente para estimular a sua aprendizagem. Sobre comunicação e a facilitação do diálogo, a qual os docentes se referem, os relatos retratam a necessidade dessa comunicação, para o sucesso do aprendizado, e para uma boa interrelação entre professor-aluno.

Acerca disso, Freire (1996, p. 42) diz que o "educador que pensa coerente exerce como ser humano a irrecusável prática de inteligir, desafiar o educando com quem se comunica, produzindo a compreensão do que vem sendo comunicado". Nesse sentido, é possível dizer que as declarações dos docentes, corroboram com o que leciona Paulo Freire:

Somente quem escuta paciente e criticamente o outro, fala com ele, mesmo que, em certas condições, precise falar a ele. $\mathrm{O}$ que jamais faz quem aprende a escutar para poder falar com é falar impositivamente. [...] $\mathrm{O}$ educador que escuta aprende a difícil lição de transformar o seu discurso, às vezes necessário, ao aluno, em uma fala com ele (Freire, 1996, p. 113 - grifos do autor).

Freire (1996) ainda ensina que a relação de respeito à dignidade e às particularidades do educando se dá via dialógica, uma vez que é apenas por meio do diálogo, e de uma boa intercomunicação professor-educando, é que se torna possível alcançar os objetivos esperados, de forma a gerar, espontaneamente, uma relação afetiva, pois, o professor sempre deve buscar por meio de sua fala, assim como, em suas ações e em suas gestões, trazer o aluno para perto de si e do objeto do conhecimento, sendo justamente isso, que tornará o processo de ensino-aprendizagem mais instigante e, por consequência motivador.

Nota-se que é por meio da comunicação, do diálogo, entre professor e aluno, que surge a afetividade propiciando a troca de conteúdo entre os mesmos, gerando um processo de conhecimento mais envolvente, fazendo com que os alunos sejam motivados; e, haja maior compreensão do conteúdo, evidenciando a Aprendizagem Significativa.

De acordo com Kieckhoefel (2011), para transformar as diferenças em possibilidade de aprendizagem é necessário compreender que ensinar é um processo no qual professor e aluno, devem "entrar em acordo" na troca e na mediação do conhecimento. Esse "acordo" é condição fundamental e imprescindível para que o saber seja proveitosamente trabalhado.

Alves (2004) defende a afetividade como inerente à pedagogia afetivamente significativa. Para o autor, toda a experiência de aprendizado tem seu início embasado em uma experiência afetiva; e nesse pensamento nasce do afeto. Deste modo, é inegável e incontestável a importância das relações dentro do processo de ensino-aprendizagem. 
Analisando os relatos dos docentes participantes deste estudo, verifica-se que os mesmos atuam buscando uma escuta diferenciada de seus alunos, buscando proximidade, gerando sentimentos de afeto, tendo em vista, uma Aprendizagem Significativa.

Percebe-se ainda, que esse processo de interação entre professor-aluno, e suas respectivas evoluções na aprendizagem são capazes de desenvolver, também, uma relação de respeito entre si, a qual posteriormente podem vir a modificar a relação sociocultural e profissional do estudante na sociedade.

\section{Considerações Finais}

Os docentes participantes do estudo, veem muitas qualidades positivas e saberes próprios que auxiliam para a efetiva construção do conhecimento; na visão dos mesmos, para que haja um ensino coerente, é imprescindível considerar o estado inicial dos alunos, seus conhecimentos prévios e esquemas de conhecimentos construídos. Ao analisar a relatos obtidos, percebe-se que, o início do processo educativo está em conhecer o que se tem para sobre essa base, construir o novo, e isso, na visão dos mesmos, só é possível com laços afetivos sólidos entre professor-aluno. Assim, é possível contribuir para uma abordagem mais integrada e ampliada para se compreender os significados da afetividade dentro do processo de ensinoaprendizagem.

Com os resultados preliminares da pesquisa, evidenciam a necessidade em se buscar para priorizar as relações professor-aluno visando estimular os laços afetivos entre ambos, como uma ferramenta de fundamental importância no ensino, na qual compete ao professor emprega-la em seu benefício, fazendo com que seus alunos tenham um maior interesse em sua disciplina, assim como tenham um maior desenvolvimento intelectual. Nesse sentido, acredita-se que, a afetividade seja capaz de promover mudanças expressivas, ainda sendo um facilitador da Aprendizagem Significativa; uma vez que, o estudante se desenvolve de modo significativo quando tem prazer no que faz, ou no que aprende.

O desenvolvimento da pesquisa vem, ao longo de seu curso, demonstrando, que as práticas docentes, de modo geral, precisam considerar a afetividade, bem como as emoções de modo geral, como premissa para a aquisição da aprendizagem; e de maneira especial uma Aprendizagem Significativa. Nesse sentido, é preciso compreender que nem todos os indivíduos aprendem uma mesma coisa ao mesmo tempo, e da mesma maneira. Em razão disso, é importante oferecer diferentes formas de trabalhar os conteúdos, onde cada aluno construirá seu conhecimento de acordo com suas habilidades, e sobretudo com base nos conhecimentos que o mesmo já dispõe acerca daquele conteúdo.

Em estudos futuros, considera-se importante um aprofundamento desse estudo em uma visão emocional, onde o professor gere uma identidade de afetividade em que o processo ensino-aprendizagem englobe o aluno não só no aspecto intelectual, mas o afetivo, emocional e social e que por certo promova habilidades e competências sócio emocionais, que irá contribuir para uma aprendizagem duradoura e significativa.

\section{Referências}

Agra, G., Formiga, N. S., Oliveira, P. S., Costa, M. M. L., Fernandes, M. G. M. \& Nóbrega, M. M. L. (2019). Análise do conceito de Aprendizagem Significativa à luz da Teoria de Ausubel. Rev Bras Enferm., 72 (1), 258-265.

Alves, R. (2004). O desejo de ensinar e a arte de aprender. Fundação EDUCAR DPaschoal.

Antunes, C. (2006). A afetividade na escola: educando com firmeza. Maxiprint.

Antunes, A. C. J. (2016). A afetividade na relação professor-aluno: aprendizagem potencializada e construção de significados. (Trabalho de Conclusão de Curso). Universidade de Brasília, 2016.

Ausubel, D. P. (1963). The psychology of meaningful verbal learning. Grune and Stratton. 
Ausubel, D. P., Novak, J. D. \& Hanesian, H. (1980). Psicologia educacional. Interamericana.

Bardin, L. (2016). Análise de conteúdo. Edições 70.

Carvalho, E. T., Maciel, C. M. L. A. \& Herrea, M. R. G. (2017) La afectividad como potenciadora del aprendizaje. Revista Gestão Universitária, 7. 1-4.

Figaro, R. (2012). Comunicação e análise do discurso. Contexto.

Freire, P. (1996). Pedagogia da autonomia: saberes necessários a prática educativa. Paz e Terra.

Gil, A. C. (2010). Como elaborar projetos de pesquisas. Atlas.

Kieckhoefel, J. C. (2011). As relações afetivas entre professor e aluno. Anais do 10 Seminário Nacional de Educação - X Educere, Curitiba, $2533-2543$.

Lakatos, E. M. (2008). Metodologia científica. Atlas.

Maldonado, M. T. (1994). Aprendizagem e afetividade. Revista de Educação AEC, 23 (91), 37-44.

Moreira, M. A. (2005). Aprendizagem significativa subversiva. Indivisa - Boletín de Estúdios e Investigación, 6, 83-101.

Moreira, M. A. (2006). A teoria da aprendizagem significativa e sua implementação em sala de aula. Editora UnB.

Moreira, M. A. \& Mansine, E. F. S. (2001). Aprendizagem significativa: A teoria de David Ausubel. Centauro.

Nery, M. A. (2009). Penso e sinto, logo aprendo: a relação afetiva entre professor-aluno na aprendizagem. (Monografia). Universidade Federal da Bahia, Salvador, BA, 2009.

Piaget, J. (1980). Psicologia e epistemologia. Forense.

Portelada, A. F. S. (2011). As emoções a nível escolar. International Journal of Developmental and Educational Psychology, 1 (1), $69-78$.

Rodrigues, S. A. \& Garms, G. M. Z. (2007). O lugar da afetividade no ambiente de aprendizagem: desafio da prática docente. Revista Ibero-Americana de Estudos em Educação, 1 (2), 231-239.

Rodrigues, M. (1976). Psicologia educacional: uma crônica do desenvolvimento humano. Mc Graw- Hill do Brasil.

Silveira, L. R. P. (2010). A importância da afetividade na relação professor-aluno para a construção de uma aprendizagem significativa. (Trabalho de Conclusão de Curso). Universidade Federal do Rio Grande do Sul.

Sousa, P. B., Santos, F. C. \& Valverde, C. (2016). A influência da afetividade no processo de aprendizagem. Revista Pedagogia em Foco, 11 (6), 168-179.

Veras; R. S. \& Ferreira, S. P. A. (2010). A afetividade na relação professor-aluno e suas implicações na aprendizagem, em contexto universitário. Educar em Revista, 38, 219-235.

Yin, R. K. (2015). Estudo de caso: planejamento e métodos. Bookman. 